\title{
An assessment of accessibility of the low-income areas within the urban form in South Africa
}

\author{
I. M. Röntgen \\ North West University, Potchefstroom Campus, South Africa
}

\begin{abstract}
In terms of the Integrated Development Planning (IDP) process in South Africa sectoral plans are being prepared as a forward planning mechanism to integrate land use, transportation planning and service delivery. The instruments used to align and integrate the process are the Spatial development framework (SDF) and Integrated Transport Plan (ITP) that, in the case of this paper, were prepared for the area of jurisdiction of the City of Tlokwe Local Municipality.

The paper focuses on an assessment of the spatial components included in the SDF and the ITP so as to promote accessibility and movement of people, goods and services. The accessibility of the low-income residential areas is quantified and qualified based on an independent traffic survey case study related to all access routes (Class 3 and Class 4 roads) in terms of predominant movement between origin and destination (residential nodes and places of work) within the urban structure of the study area. The findings are used to assess the nature and/or structuring components of the spatial system based on dominant land use and traffic movement patterns (inclusive of transportation infrastructure).

The paper is concluded with some general recommendations that will be of value in the implementation of similar case studies in intermediate towns within national spatial systems and revision of the City Council of Tlokwe IDP, SDF and ITP.

Keywords: accessibility, modeling, simulation, transport planning, land use planning, transportation plans.
\end{abstract}




\section{Introduction}

From Abraham [1] it follows that access is more difficult to measure than vehicle traffic and mobility because it is affected by a variety of factors, including proximity, transportation choice and travel costs. Therefore, evaluating accessibility requires integrated transportation/land use models that incorporate both physical and economic factors. This will enable the calculation and comparison in terms of changes in total costs that result from upgrading in the transportation systems based on the envisaged or planned land use patterns.

The basis for this study follows from the notion that during interview surveys of the general transportation system demand and supply indicate high levels of dissatisfaction amongst users of public transport systems in low income areas (cf. [3] and [4]). Furthermore, it follows from [3] and [4] that transportation plans must be developed to discourage urban sprawl where public transport services are inadequate and that it should be given higher priority to public transport than private transport.

From [5] it follows that a Spatial development framework (SDF) is the preparation of plans aimed at guiding, directing or regulating all land development activities in a defined area in order to determine or influence the spatial consequences of such land development activities.

Integrated transport plan (ITP) means an integrated transport plan contemplated in section 36 of the NLTA and includes proposals related to transportation planning, passenger transport strategy and transportation infrastructure development (see [4]).

\section{Spatial and transportation planning}

\subsection{The integrated development plan process}

Figure 1 shows the components of the integrated spatial, transportation and environmental planning process as being applied in South Africa.

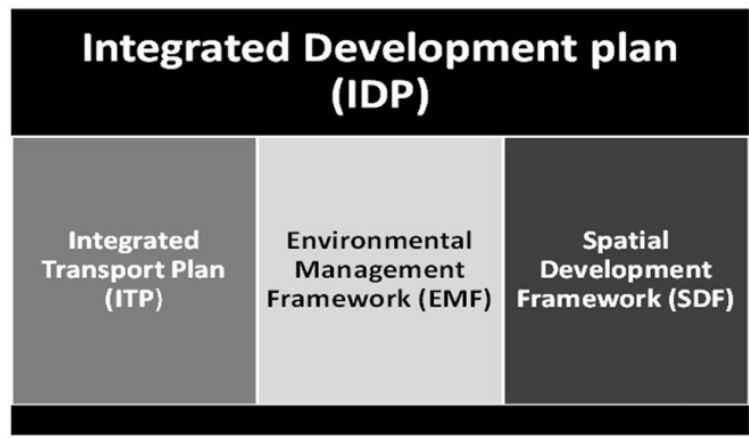

Source: Own construction.

Figure 1: Components of the integrated spatial planning process as applied in South Africa. 


\subsection{Sectoral plans as included in the case study}

In order to understand the underlain relationships between the sectoral plans of transport, spatial planning (land use management) and service delivery the input of the following existing knowledge within the study area is used (refer also to Figure 1 above):

- $\quad$ Tlokwe City Council SDF (Spatial Development Framework): Figure 2 shows the SDF for the Tlokwe City Council (TCC) [6].

- $\quad$ Tlokwe City Council ITP (Integrated Transport Plan):

Figure 3 shows the contents of the TCC Draft ITP [6].

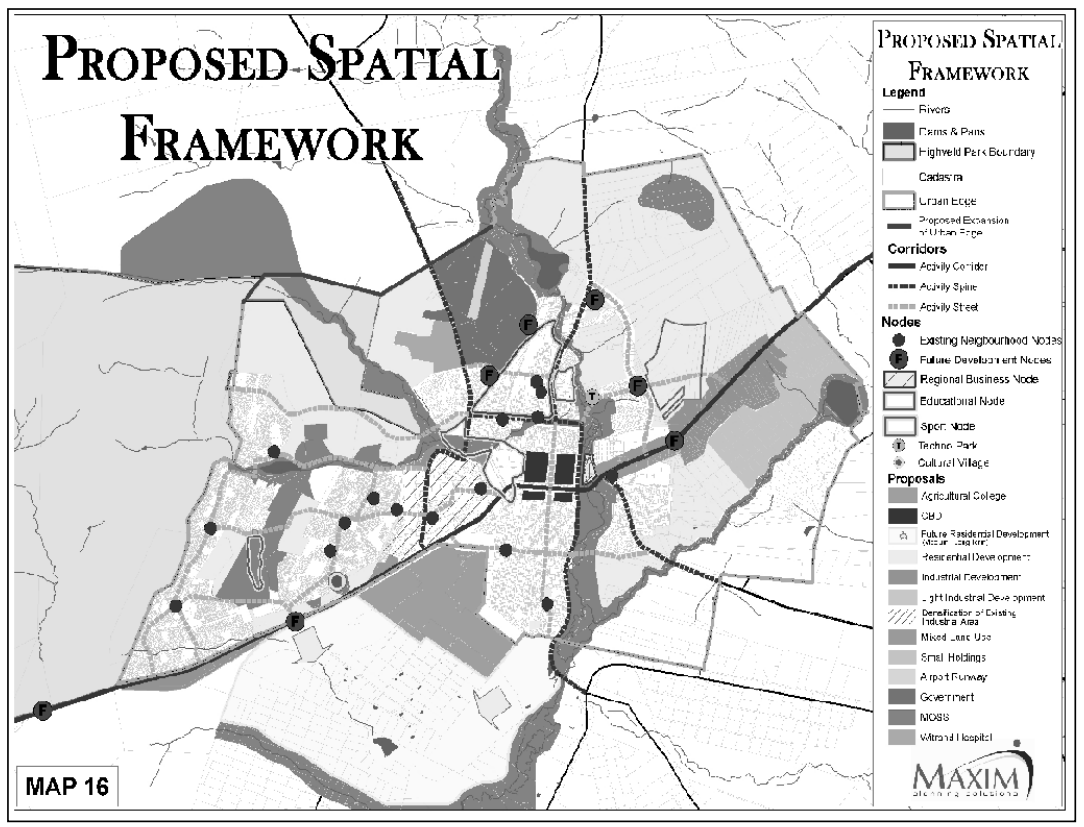

Source: [6]

Figure 2: $\quad$ Tlokwe city council draft SDF.

The contents of the TCC Draft ITP 2008 are shown in Figure 3. Of importance to this paper is the integration between the SDF and the IDP as shown in both Figure 2 and Figure 3.

\section{Case study: traffic impact assessment (TIA) to measure accessibility}

From the contents of the figures the traffic survey points as shown in Figure 4 were selected in order to assess the accessibility between the low income residential areas and the urban structure. The low income areas for the purposes 


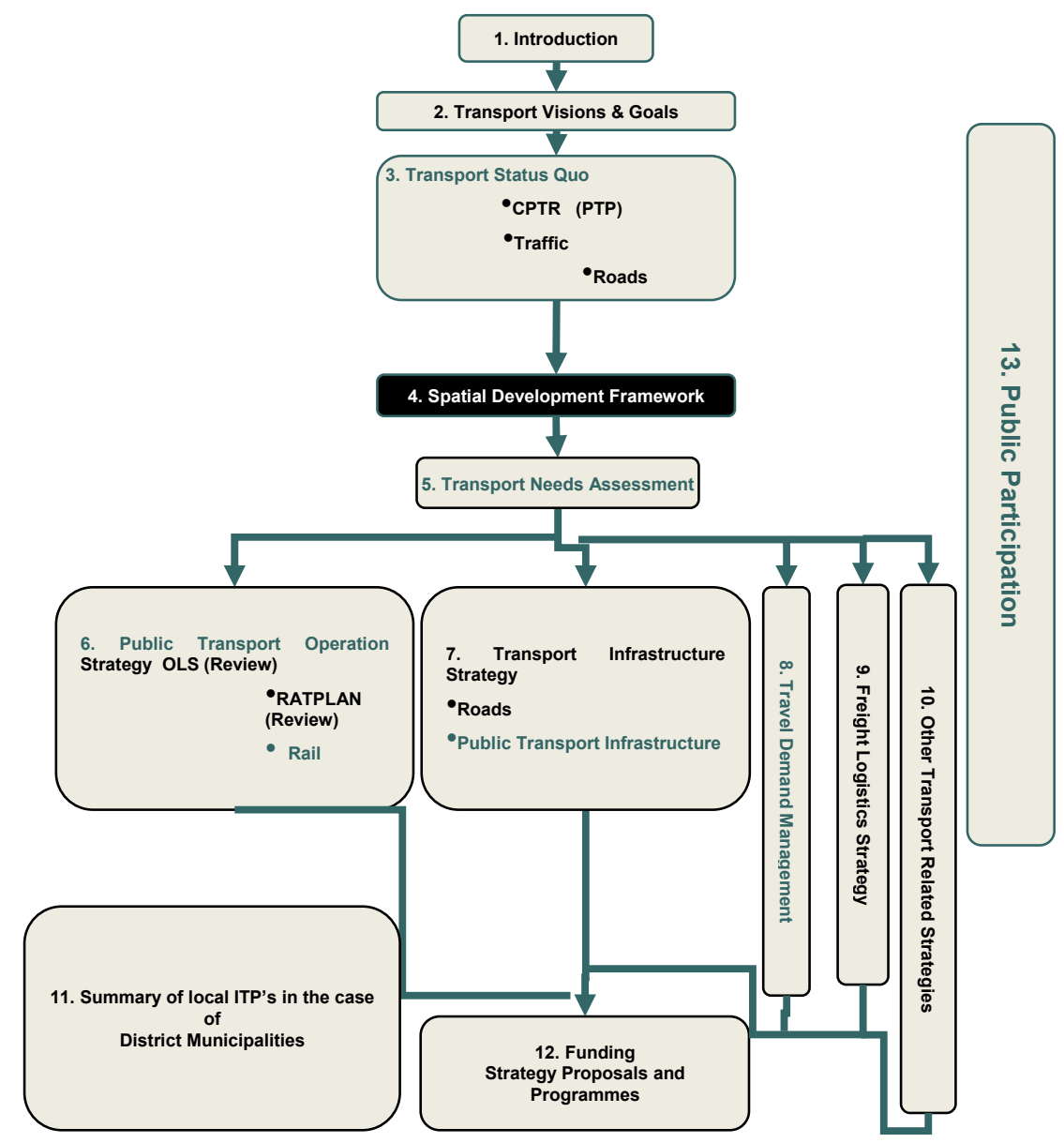

Source: [6]

Figure 3: Draft ITP content and process of TCC.

of this paper represent the origin of trips generated whilst the rest of the urban structure serves as the destination (am peak traffic). During the afternoon (pm peak traffic) the position reverse. Off-peak traffic moves between the origin and destinations as identified and vice versa. As will be illustrated a clear distinction is made between intra-traffic (internal) and inter-traffic (through traffic) movements within the study area. The Class 1,2 and 3 roads in the study area practically operate as Class 4 roads and are therefore recorded as such in Figure 4. 


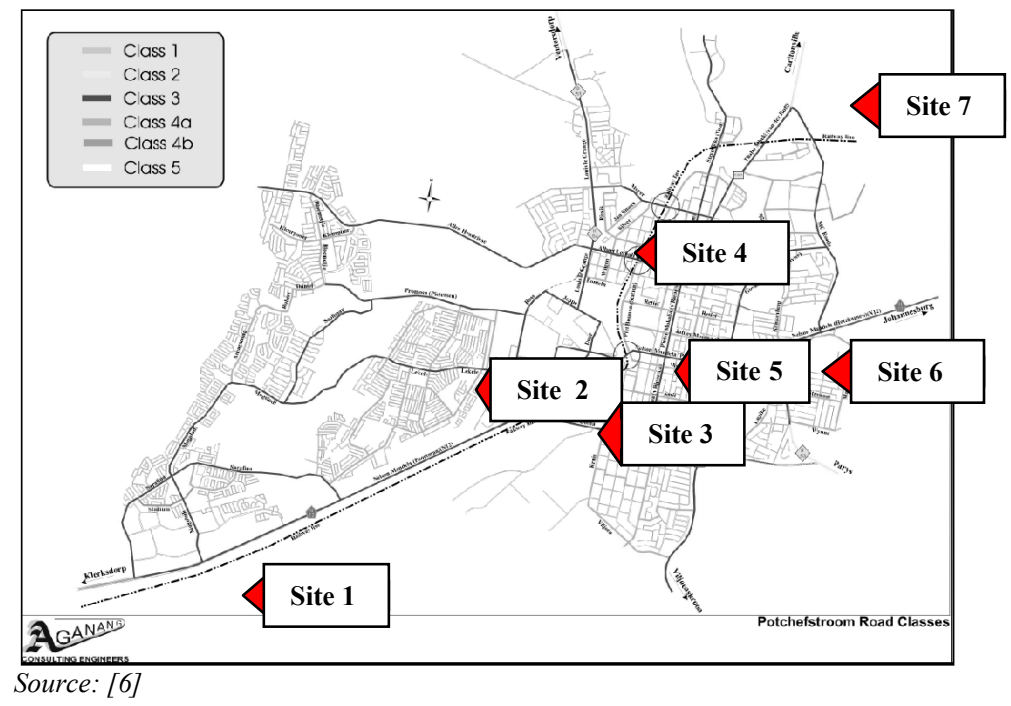

Figure 4: Road classes within the TCC indicated the traffic survey points selected for the case study.

\section{Traffic survey case study}

The study area was based on seven sites as in Figure 4. A traffic survey was conducted to observe traffic flow operations. Manual traffic counts were performed simultaneous in October and November 2010 on all seven sites on a Tuesday and Thursday, to ascertain existing traffic volumes patterns. The morning peak hour occurred between $6 \mathrm{~h} 45$ and $7 \mathrm{~h} 45$ and the afternoon peak hour occurred between $16 \mathrm{~h} 30$ and $18 \mathrm{~h} 00$.

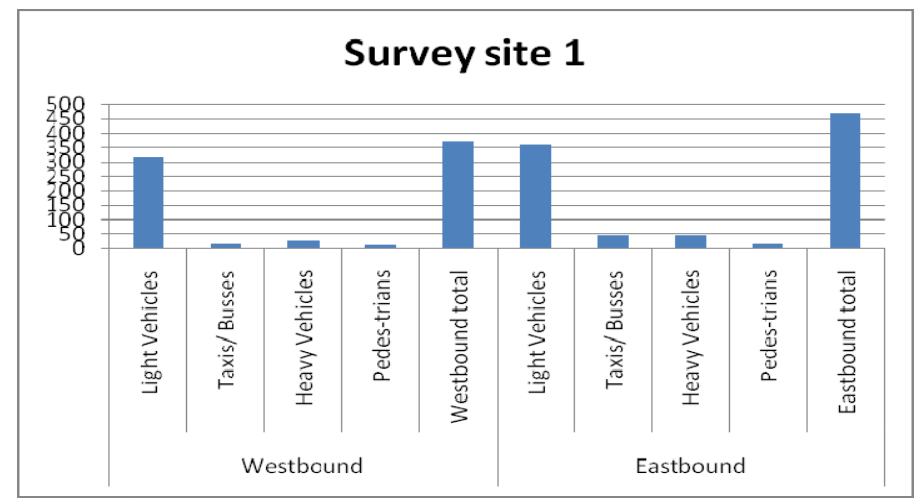

Source: Own construction.

Figure 5: $\quad$ Modal split of peak hour traffic for survey site 1. 

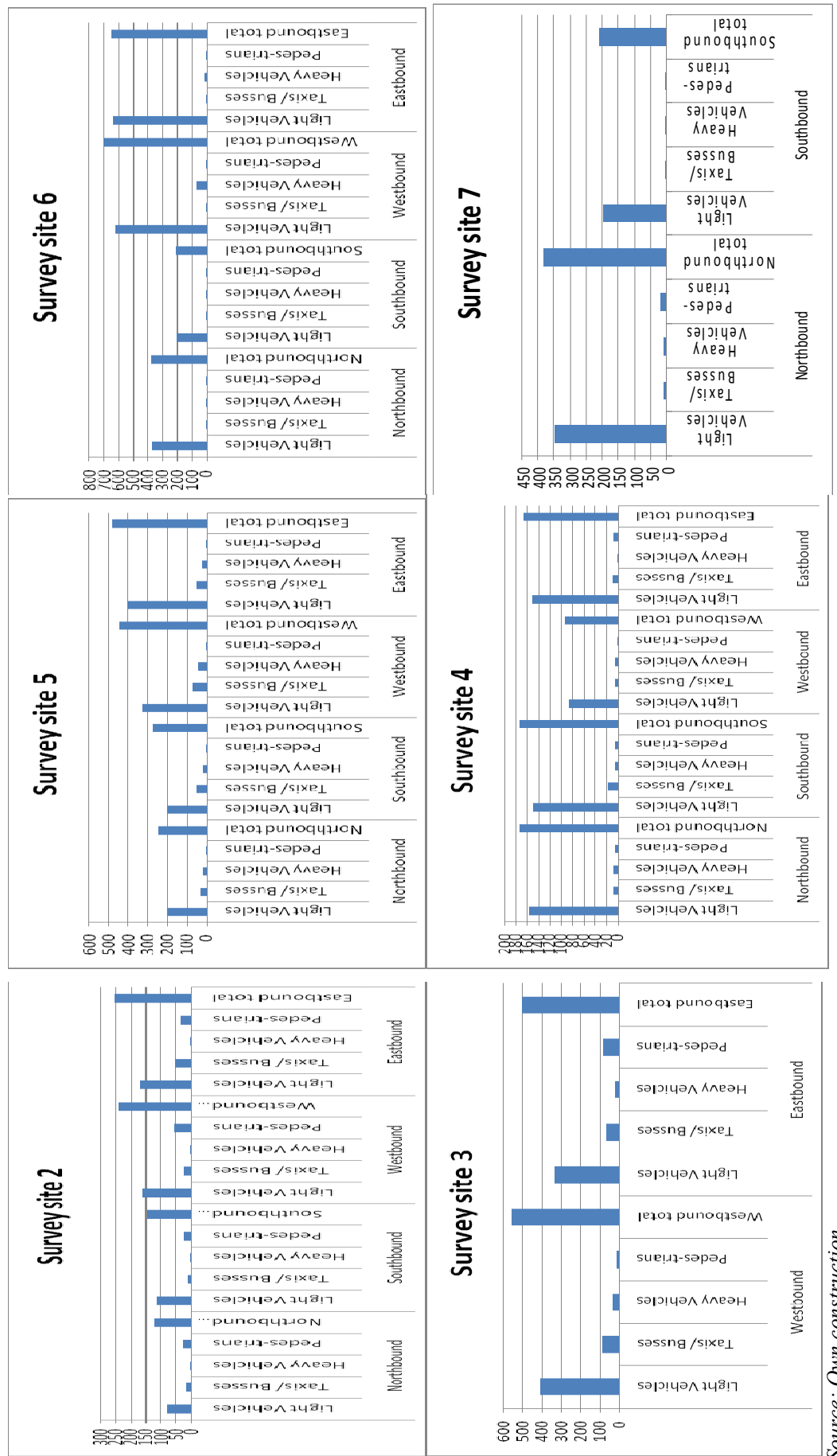


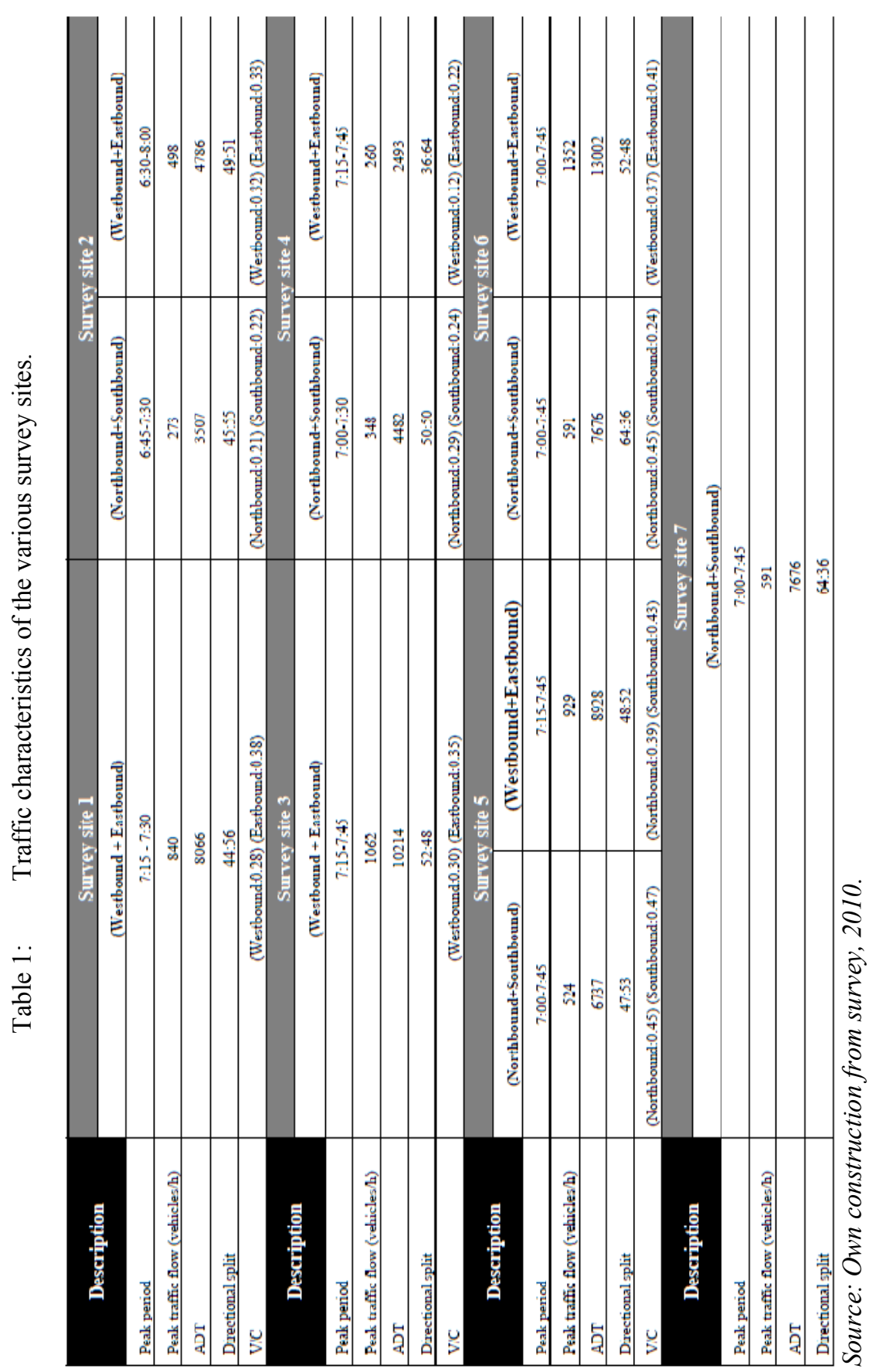




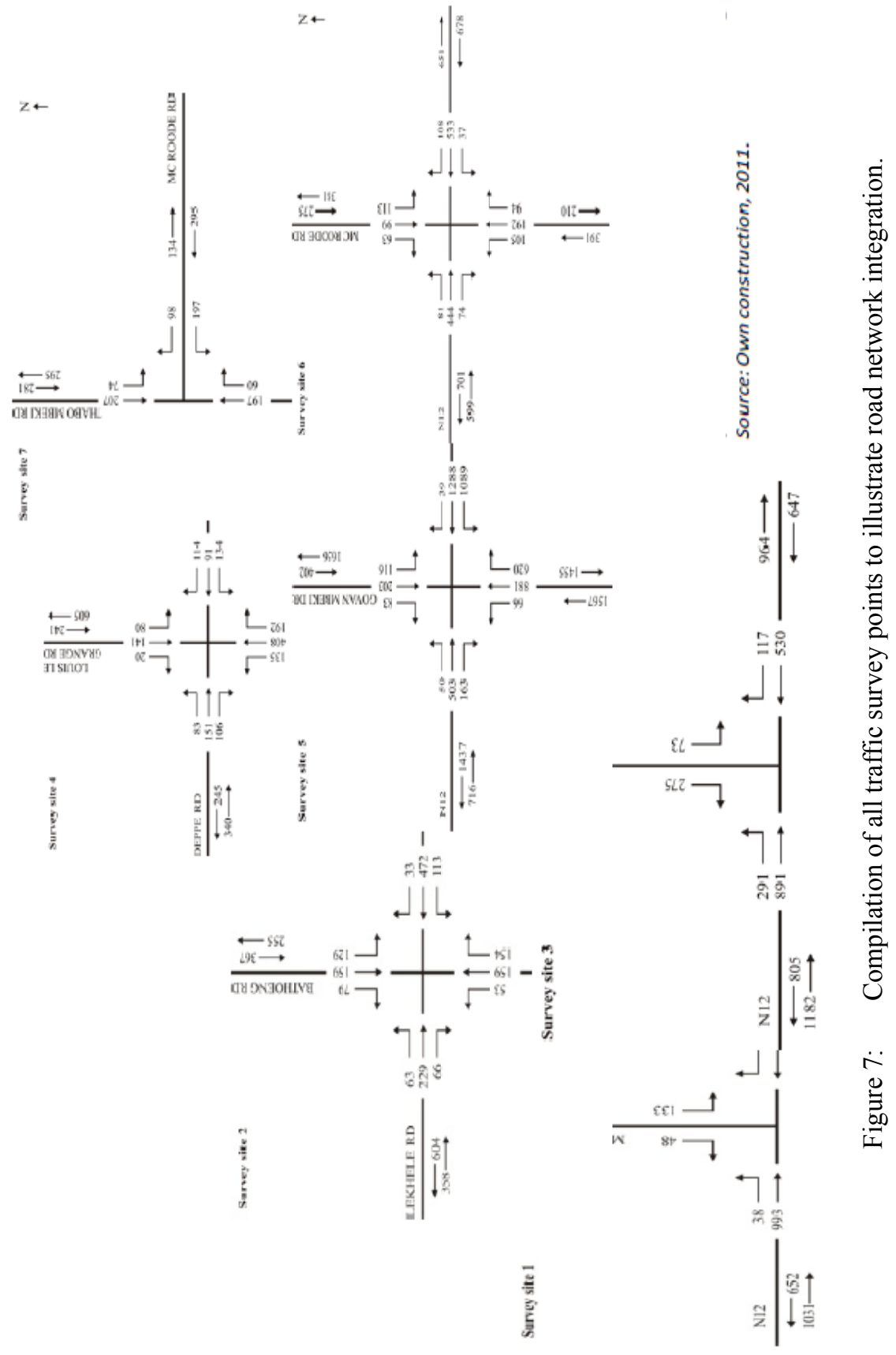


The modal split for the morning peak hour (refer to Figure 5 and Figure 6) in terms of the survey data consisted of light passenger vehicles, minibus - taxis, heavy motor vehicles and pedestrians. It is clear that light vihicles usage is the highest at all the various survey sites. At survey sites 1 and 2 (see Figure 5, Figure 6 and Figure 7) the eastbound traffic is the highest.

For the morning peak hour the eastbound traffic flow due to the informal settlement forms $67 \%$ of the total eastbound peak hour traffic flow. Table 1 illustrates the modal split for the morning peak hour traffic due to the informal settlement at that respective survey sites.

\subsection{The quantification and qualification of the accessibility}

From abovementioned Table 1 supported by the data as included in Figures 5 and 6 the conclusion can be drawn that notwithstanding the existence of the SDF and ITP die low income residential areas located to the east of the urban structure is depended on public transport as predominant mode between origin and destination (workplace). This dependency is further supported by the indicators of travelling cost and travelling time that will be discussed hereunder.

\subsubsection{Travel cost and time}

From the traffic survey it became evident that travel cost and time in terms of traffic movement between the low income residential areas and the rest of the urban structure is problematic. Some $73 \%$ of the economic active population that resides within the low income residential areas make use of public transport (minibus-taxi mode) between origin and destination. On average such respondents pay between R18-50 (shorter distances than 10km) and R34-00 (longer distances of $22 \mathrm{~km}$ ) per day for travelling costs. This amounts on average monthly travelling expenditure of R525/month or $29.16 \%$ of gross income for formally employed persons. Persons informally employed earn on average some $\mathrm{R} 115 /$ day or $22.82 \%$ of their daily income is spent on transport.

A further phenomenon from the traffic survey relates to the distance users of public transport have to cover in order to access the public transport facilities. These trips are generally made through walking and take between 15 minutes and 45 minutes per day. This is the direct result of the fragmented urban form.

\subsubsection{Volume-to-capacity}

From Banks [2] it follows that the $\mathrm{V} / \mathrm{C}$ ratio depicts the volume of vehicles in relation to the available road capacity. A vehicle to capacity ratio that is greater than 0.95 indicate insufficient capacity to accommodate vehicles, resulting in excessive queues and delay.

In Table 2 the current $\mathrm{V} / \mathrm{C}$ ratios are determined. The intersections capacity was evaluated and measured in accordance with the Highway Capacity Manual (refer to [7]).

\subsubsection{Traffic growth}

By using 2009 and 2010 data of the same location on the N12 an annual discretely compounded traffic growth rate of $2.7 \%$ was calculated. 


\subsubsection{Traffic forecast}

Due to the fact that the annual growth within the low income area is at present calculated at $3.78 \%$ and if the modal distribution prevails, the existing access roads and thus the accessibility to the area will increase traffic volumes on the N12 route. Other access roads will suffer based on present geometrical and structural road standards that are already showing a lack of capacity and service ability.

\subsubsection{Profile of population}

In assessing the abovementioned conclusions the existing socio-economic profile of the study area the demographic structure, income levels, education and vehicle ownership patterns should be considered. From the 2007 population census (refer to [8] and for 2003 to [9]), the Tlokwe LM in 2010 consists of approximately 254000 persons. The annual income of $75 \%$ of the households are less than R30 000. The largest percentage employment is in Community Service $40 \%$, followed by Trade some $20 \%$ and Household some $14 \%$. Unemployment in the study area is estimated to be in access of $29 \%$ of the economic active population. This profile underpins the need to promote an affordable and improved public transport system that will provide passengers with the option of modal choice.

\section{An integration approach}

The research results will be tested based on scenario formulation and will include a simplified modeling and simulation exercise focusing on land use, traffic movement patterns and provision of infrastructure to address future demand and needs. The research results will reflect on the accessibility and mobility levels within the urban structure and form. The effectiveness, efficiency and sustainability of the future spatial and transportation planning (SDF and ITP) framework will be analyzed and assessed. This task is at present being undertaken.

\section{Recommendations}

In terms of passenger operations, there are two types of capacity utilisation problems that need to be addressed, namely service capacity and available infrastructure capacity. The former deals with the utilisation of the supply of seats of vehicles in terms of the mini-bus taxi mode of transport whilst the latter deals with the ability of available infrastructure address the need exerted by the traffic volume increases in all modes of transport.

Passenger transport service supply problems can be solved in various ways, including increasing frequencies, re-routing of vehicles from over-supplied routes to under-supply routes; increasing the vehicle fleet or introducing more efficient scheduling. The lack of modal choice clearly indicates that the TCC should consider having a detailed Passenger Transportation Plan to be prepared to support the IDP. 
Infrastructure capacity problems on the other hand can be addressed through road network improvements and infrastructure provision for specific modes of transport, with improved horizontal and vertical alignment between the IDP and its sectoral plans (SDF, ITP and Passenger Transport Plan).

Practical and feasible road improvements and maintenance is recommended to ensure acceptable operating service levels of the total road network. The conclusions and recommendations contained in this paper will inform the Tlokwe City Local Municipality on ways to amend the SDF and ITP as to optimize traffic movement and mobility between the spatial components and thus to ensure urban integration and normalization.

\section{References}

[1] John Abraham, Review of the MEPLAN Modelling Framework from a Perspective of Urban Economics, Civil Engineering Research Report CE982, University of Calgary, 1998, www.acs.ucalgary.ca/ jabraham/ MEPLAN_and_Urban_Economics.PDF.

[2] James H. Banks, Introduction to Transportation Engineering, Second Edition, McGraw-Hill, 2004.

[3] Department of Transport, 2007, Government Notice, Gazette No. 30506, National Land Transport Transition Act (22 of 2002): Integrated Transport Plans: Minimum requirements for preparation of integrated transport plans. Government Printer. Pretoria, 2007.

[4] Department of Transport National Land Transport Act (5 of 2009). Government Printer. Pretoria, 2009.

[5] Land Use Management Bill, Government Department of Land Affairs. Government Printer, Pretoria, 2003.

[6] Tlokwe City Council IDP 2007; SDF 2008 and ITP, 2008.

[7] Transportation Research Board: National Research Council, Washington DC, Highway Capacity Manual, 2000.

[8] Transport plans for Potchefstroom in support of the Southern district Integrated Transportation Plan, Potchefstroom City Council, 2007.

[9] StatsSA, Community Census 2007 and Mid Year Estimates for Tlokwe LM, 2010. 